\title{
UNHA ANÁLISE MACROECONÓMICA DA ACUMULACIÓN DE CAPITAL EN ESPAÑA DURANTE A FASE DE EXPANSIÓN (1995-2007)
}

Juan Pablo MATEO

Visiting scholar, Department of Economics, The New School (Nueva York, EE.UU.)

Email: mateoj@newschool.edu

\section{Resumo}

Neste artigo lévase a cabo un estudo do proceso de acumulación de capital na economía española durante o período 1995-2007. O obxectivo é analizar os desequilibrios dun modelo económico baseado no auxe do prezo dos activos asociados á construción, principalmente de tipo residencial, tendo en conta o papel central que tivo no crecemento económico desta fase. $\mathrm{O}$ estudo realízase a partir da relación entre o investimento, a produtividade e os índices de prezos, para revelar as características específicas da acumulación de capital en España. Amósase a importancia da composición do investimento, así como a reconfiguración da estrutura económica para explicar os diversos desequilibrios que se xeraron nestes anos.

Palabras chave: acumulación de capital, burbulla inmobiliaria, produtividade, España

\section{A MACROECONOMIC ANALYSIS OF CAPITAL ACCUMULATION IN SPAIN ALONG THE GROWTH PHASE (1995-2007}

\begin{abstract}
This article presents a study of the process of capital accumulation in the Spanish economy during the 1995-2007 period. The objective is to analyze the imbalances of an economic model based on the rise in the price of assets associated with construction, mainly residential, given the central role it has played in the economic growth during that period. The study is carried out using the relationship between investment, productivity, and price indexes, to reveal the specificities of capital accumulation in Spain. We highlight the importance of the composition of investment, together with the divergence between the different price indexes as well as the reconfiguration of the economic structure, in order to explain the different imbalances that have been generated over this period.
\end{abstract}

Key words: capital accumulation, housing bubble, productivity, Spain

\section{Introdución}

Neste artigo lévase a cabo unha análise macroeconómica da economía española a partir do proceso de acumulación de capital para o período de expansión que antecede á Gran Recesión (1995-2007). O obxectivo é revelar os trazos fundamentais da dinámica de acumulación de capital dende a perspectiva da produtividade, do cal se deriva unha estrutura determinada de custos de produción, e que á súa vez incide sobre o crecemento económico. $\mathrm{O}$ documento céntrase nas particularidades da evolución e estrutura do stock de capital, tendo en conta o papel central que tivo o auxe dos prezos dos activos asociados á construción, entre os que destacan os de tipo residencial. 
Para iso, analízase a evolución do stock neto de capital fixo non residencial ( $K_{\mathrm{N} n r \text { r }}^{f}$ que proporciona a FBBVA (2014),ㄹ e utilízanse diversas categorías económicas relacionadas entre elas a partir das series do INE (2014):

i) A ratio capital-traballo $\left(\theta=\mathrm{K}^{*} / \mathrm{L}\right)$, sendo $\mathrm{L}$ a cantidade de traballo ou emprego equivalente, e $\mathrm{K}^{*} \mathrm{o}$ stock a prezos constantes;

ii) a produtividade laboral $\left(\pi=\mathrm{Y}^{*} / \mathrm{L}\right)$, que relaciona o produto interior bruto $(\mathrm{Y}$, ou PIB) a prezos constantes, co L; e a produtividade do capital ( $\Pi=\mathrm{Y} / \mathrm{K})$, ou á inversa, a ratio capital-produto $(\mathrm{K} / \mathrm{Y})$, os dous a prezos correntes;

iii) a eficiencia produtiva do investimento $(\mathrm{EPI}=\pi / \theta)$; que mide o incremento da produtividade laboral derivada da mecanización introducida;

iv) a evolución de diversos deflactores de prezos de produto $\left(\mathrm{P}_{\mathrm{Y}}\right)$, o capital $\left(\mathrm{P}_{\mathrm{K}}\right)$ e o consumo $\left(\mathrm{P}_{\mathrm{C}}\right)$.

Se eludimos a depreciación e outras continxencias, a acumulación de capital defínese como o reinvestimento (I) dunha parte do beneficio (B) obtido, o que implica un incremento do stock de capital $(\mathrm{I}=\Delta \mathrm{K})$, polo que a taxa de acumulación indica o ritmo de progreso de tal stock $(\Delta \mathrm{K} / \mathrm{K})$. 0 estudo deste proceso é especialmente relevante xa que o crecemento económico en España na fase que estudamos estivo impulsado por unha intensa acumulación de capital. Pero ao mesmo tempo, incorporou desequilibrios que se tornaron decisivos en canto aos febles resultados obtidos no desenvolvemento produtivo, tanto con respecto á produtividade laboral como á do capital. Ademais, non sentou as bases para a converxencia coas economías máis avanzadas da Eurozona, pero condicionou a forma de manifestación da crise e os custos sofridos pola sociedade española (remitimos a Mateo, 2014b, 2014c).

Os estudos do proceso de acumulación que toman como referencia da análise o stock de capital, abordando o seu nivel, estrutura e evolución no tempo, e que utilizan categorías económicas asociadas, foron historicamente pouco numerosos no caso español. Porén, afortunadamente están xurdindo novos traballos, malia que aínda sexan marxinais cuantitativamente, pero que contribúen a paliar esta anomalía. Neste senso, é de agradecer o esforzo da Fundación BBVA (FBBVA), en colaboración co Instituto Valenciano de Investigacións Económicas (IVIE), na elaboración de series de investimentos e stock de capital de longo prazo e moi desagregadas por tipo de activo, ramas e dimensión xeográfica, así como unha serie de traballos moi ilustrativos sobre a acumulación de capital en España (véxase por exemplo, Mas, Pérez e Uriel, 2013). Estas series, en constante actualización dende os anos noventa, completan e melloran as elaboradas con anterioridade (como poden ser Baiges, Molina e Sebastián, 1987; Corrales e Taguas, 1989; ou Martín e Moreno, 1991).

O traballo organízase en dúas partes. O primeiro apartado amosa o marco xeral da economía española no período 1995-2007 a partir do crecemento económico e do investimento. Posteriormente, trátase o stock de capital e a evolución do conxunto de variables obxecto de estudo, para expoñer despois as principais conclusións.

1 Se non se especifica, utilizaremos K para representar o tipo de stock de capital citado. 


\section{Crecemento económico e formación de capital}

O crecemento económico de España nos trece años que discorren entre 1995 e 2007, do 3,7\% anual, foi certamente destacado en relación coa Eurozona, a Unión Europea, e en xeral o conxunto de economías avanzadas (FMI, 2013). Na táboa 1 amósase a evolución do PIB dende a perspectiva da demanda, tanto na composición, conforme aos tipos de gasto a prezos correntes, como na taxa de variación a prezos constantes. Cabe resaltar o incremento da formación bruta de capital fixo (FBCF), que chega ao 30,7\% do PIB en 2007, e cunha taxa de incremento anual medio do 6,1\% anual. Así pois, mesmo en termos cuantitativos o motor da economía española non foi o auxe do consumo, como tampouco o gasto estatal.

Porén, revélase unha certa asimetría no rol do investimento en canto á composición do PIB e á dinámica de incremento, isto é, entre a evolución do investimento a prezos correntes e a prezos constantes. O incremento de 9,2 puntos porcentuais na súa participación no produto (un $42 \%$ ) contrasta co seu menor dinamismo en termos reais con respecto ao resto de variables da demanda. ${ }^{2}$

Figura 1. Estrutura e evolución do PIB pola banda da demanda

Gasto en porcentaxe do PIB a prezos correntes e taxas de variación anual medias

\begin{tabular}{|c|c|c|c|c|c|}
\hline & \multicolumn{2}{|c|}{$\%$ del PIB } & \multicolumn{3}{|c|}{ TVA promedio } \\
\hline & & & 1995-200 & & \\
\hline & 1995 & 2007 & & $1996-00$ & 2003-07 \\
\hline PIB & 100 & 100 & 3.70 & 4.11 & 3.60 \\
\hline Consumo & 59.30 & 56.50 & 3.91 & 3.92 & 4.32 \\
\hline Gasto público & 18.00 & 18.30 & 5.62 & 7.58 & 4.47 \\
\hline FBCF & 21.50 & 30.70 & 6.08 & 7.18 & 5.99 \\
\hline $\mathrm{X}$ bys & 22.40 & 26.90 & 6.69 & 10.18 & 5.02 \\
\hline$M$ bys & 22.40 & 33.60 & 9.23 & 12.26 & 8.88 \\
\hline
\end{tabular}

Notas. FBCF: formación bruta de capital fijo; $\mathrm{X}$ : exportaciones; M: importaciones, bys: bienes y servicios. TVA: tasa de variación anual

Fuente: INE (2014)

Esta fase de expansión estivo caracterizada tamén por unha crecente integración da economía española co resto do mundo. O coeficiente de abertura pasou do 44,8 ao $60,5 \%$ do PIB, pero cun maior dinamismo das importacións. Precisemos que, deixando na marxe o cuantitativo antes sinalado, cualitativamente o investimento constitúe un requisito da competitividade que necesita a exportación, malia que tamén incide sobre as importacións, polo que o investimento está estreitamente relacionado coa dimensión externa, é dicir, coa modalidade de inserción da economía española no conxunto da economía europea e mundial.

2 Apréciase o que podemos denominar un importante "efecto prezo" no proceso de acumulación de capital nestes anos, o que permite aludir ao denominado por Brenner (2006) como "keynesianismo do prezo dos activos", ou o "modelo financeiro-inmobiliario" que sinalan Rodríguez e López (2011). 
$\mathrm{Na}$ análise da acumulación de capital (e o crecemento económico que dela se deriva) non só é pertinente o volume total de investimento, senón a composición do mesmo por tipo de activo e ramas da economía, xa que as implicacións con respecto á produtividade e rendibilidade acadada son diferentes (Mas, Péreze Uriel, 2006; Pérez e Serrano, 2010). Por tipo de activo (figura 2), destaca o investimento en construción, que chegou a unha media de dous terzos do total, con carácter ascendente ao longo do período, fundamentalmente para na epígrafe residencial, que chega a representar o $40 \%$ do total do investimento ${ }^{3}$. Asemade, os desembolsos relacionados coa maquinaria e o equipo ${ }^{4}$ só representaron un 18,9\% do total, e apenas o $15,7 \%$ entre 2003 e 2007.

Figura 2. Composición do investimento por tipo de activo

\begin{tabular}{|c|c|c|c|c|c|c|}
\hline \multirow[b]{2}{*}{ Tipo de activo } & \multicolumn{2}{|c|}{ Composición (\%) } & \multicolumn{4}{|c|}{ TVA (\%) } \\
\hline & 1995-07 & 2003-07 & 1995-07 & $1995-99$ & $2000-07$ & 2003-07 \\
\hline Total & 100 & 100 & 6.45 & 7.99 & 5.42 & 5.96 \\
\hline 1. Activos materiales & 96.01 & 95.77 & 6.35 & 7.89 & 5.33 & 5.94 \\
\hline 1.1. Viviendas & 36.02 & 40.12 & 7.29 & 9.55 & 5.59 & 4.88 \\
\hline 1.2. Otras construcciones & 31.90 & 31.36 & 4.14 & 1.57 & 5.91 & 5.74 \\
\hline 1.3. Equipo de transporte & 8.78 & 8.21 & 8.70 & 15.05 & 4.98 & 8.72 \\
\hline 1.4. Maquinaria, equipo y otros & 18.93 & 15.71 & 7.88 & 15.36 & 3.72 & 7.42 \\
\hline 1.4.1. Productos metálicos & 2.74 & 2.35 & 6.13 & 15.07 & 1.13 & 4.62 \\
\hline 1.4.2. Maquinaria y equipo mecánico & 6.48 & 5.70 & 7.18 & 16.03 & 2.37 & 5.96 \\
\hline 1.4.3. Equipo de oficina y hardware & 2.37 & 1.67 & 19.55 & 35.00 & 11.71 & 14.37 \\
\hline 1.4.4. Otra maquinaria y equipo & 7.34 & 5.98 & 7.34 & 12.70 & 4.23 & 8.08 \\
\hline 1.5. Activos cultivados & 0.38 & 0.38 & 19.74 & 31.57 & 15.13 & 10.96 \\
\hline 2. Activos inmateriales & 3.99 & 4.23 & 9.14 & 11.03 & 7.68 & 6.34 \\
\hline 2.1. Sottware & 3.31 & 3.50 & 8.86 & 11.46 & 7.92 & 6.43 \\
\hline 2.2. Otros activos inmateriales & 0.68 & 0.73 & 10.71 & 8.32 & 6.56 & 5.90 \\
\hline \multicolumn{7}{|c|}{ Nota. TVA: tasas de variación anual (\%). La composición de la inversión, a precios corrientes, y las TVA en términos constantes. } \\
\hline Fuente: FBBVA (2014) & & & & & & \\
\hline
\end{tabular}

A participación do investimento non residencial $\left(\mathrm{I}_{\mathrm{nr}}\right)$ no total perdeu 10 puntos porcentuais entre a primeira metade dos anos noventa e 2005-07. Dende principios dos años oitenta a $I_{n r}$ aumentara relativamente, pasando de representar o 61-62\% entre 1977 e 1982, a estabilizarse en torno ao 70\% a partir de 1989. Pola súa banda, o investimento nos sectores que podemos considerar como produtivos ${ }^{5}$ dende o punto de vista da valorización do capital amosou unha caída de casi 8 puntos porcentuais en 2000-07, ata 0 $46 \%$ en 2007 (fig. 3). Québrase así un ciclo relativamente estable en torno ao 50-55\% do total dende metade dos setenta.

3 En perspectiva histórica, o investimento nestes apartados non chegaba a unha media sequera do $60 \%$ do total ata a metade dos anos setenta, en plena industrialización, conforme a serie da FBBVA (2014), que comeza en 1964.

4 Facemos referencia a "Produtos metálicos", "Maquinaria e equipo mecánico", "Equipo de oficina e hardware" e "Outra maquinaria e equipos", conforme a base de datos da FBBVA (2014).

5 Se consideramos improdutivas ás seguintes ramas: actividades inmobiliarias, Administración pública, Educación, sanidade e servizos sociais públicos. Xustificaríase non polo contido material da actividade, senón por non ter un carácter mercantil (producido co obxecto de obter beneficio) ou por considerar que unha vivenda non é capital. Sobre estas cuestións, na que non profundamos aquí, remitímonos á máis completa argumentación teórica de Mateo (2008). 
Figura 3. Investimento non residencial e en ramas produtivas

Series en porcentaxes do total a prezos correntes (P corr) e constantes (P ctes)

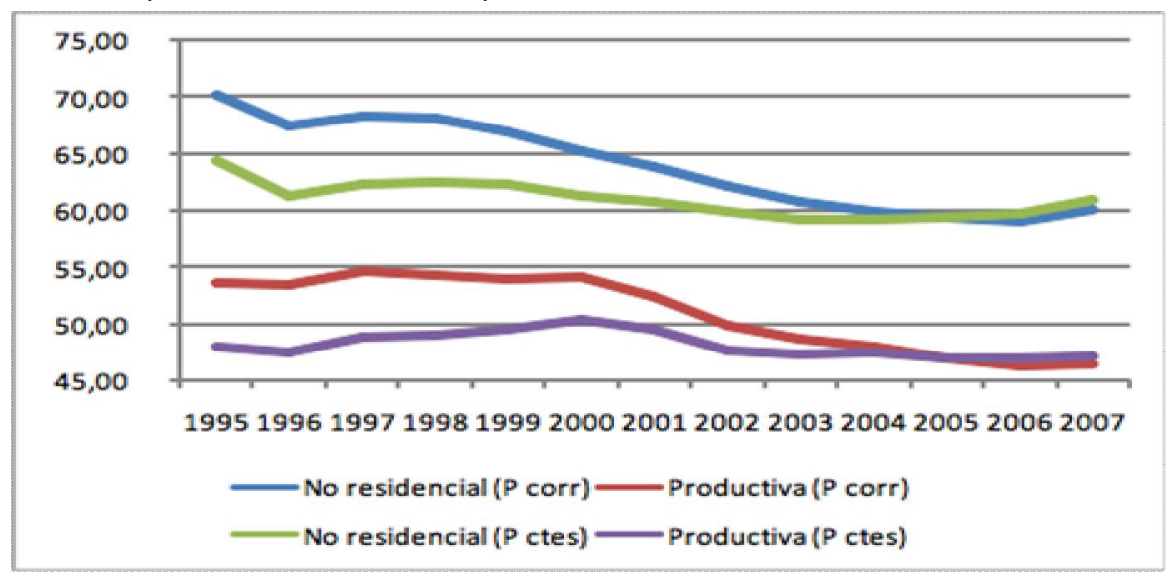

Nota. Os sectores produtivos excluirían os seguintes, segundo a numeración da FBBVA (2014): 7. Actividades inmobiliarias; 9.1. A Administración pública; 9.2. Educación pública; 9.4. Sanidade pública; 9.5. Servizos sociais públicos. Fonte: FBBVA (2014)

Resulta máis problemática o percorrido do investimento a prezos constantes, pois quebra á súa vez unha tendencia histórica de carácter á alza. ${ }^{6}$ Con breves excepcións, a $\mathrm{I}_{\mathrm{nr}}$ pasa do $35-40 \%$ na segunda metade dos anos sesenta a $64-65 \%$ durante a primeira metade dos noventa. Porén, dende 1995 baixa, para flutuar en torno ao 59-60\% do total a partir de 2001.

\section{0 proceso de acumulación de capital}

\subsection{0 stock de capital}

O stock de capital (K) a prezos constantes foise incrementado a un ritmo elevado, en xeral por enriba do 4\% anual (fig. 4). A fase posterior a 1999 é a que rexistra un maior dinamismo, tanto para activos residenciais como non residenciais.

Figura 4. Taxas de variación anual do stock neto de capital

Series do stock total e residencial en porcentaxes, a prezos constantes

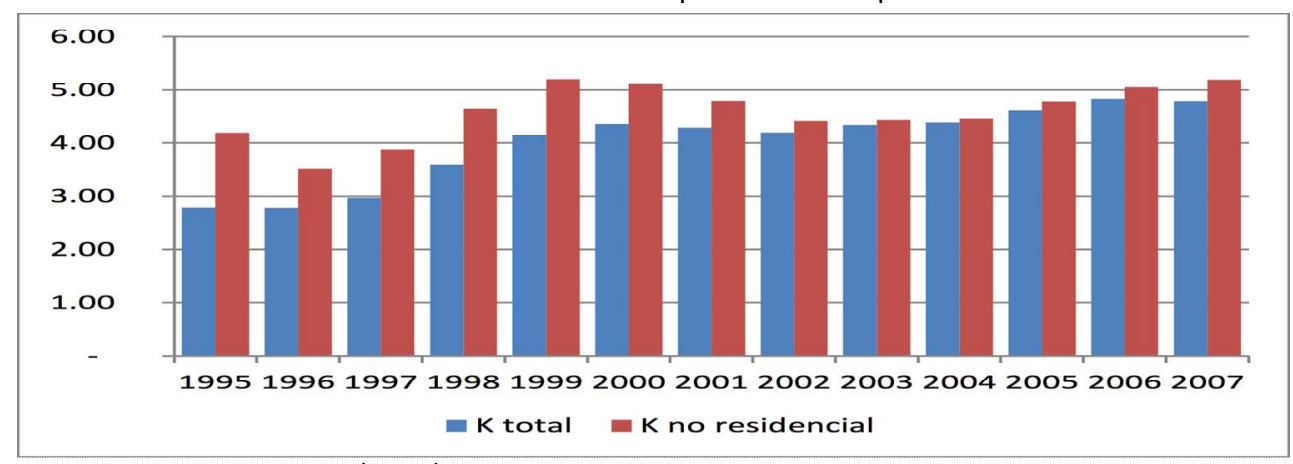

Fonte: BBVA (2014)

${ }^{6}$ Facemos referencia ao período posterior a 1964, ano no que comeza a serie homoxénea da FBBVA. 
A pesar do menor dinamismo do investimento non residencial, o efecto prezo da inflación de activos reflíctese no crecemento superior do stock a prezos constantes $\mathrm{K}_{\mathrm{nr}}$. En termos correntes, o stock non residencial representaba en 1995 o 50,1\% do total, porcentaxe que en 2007 ata será un pouco inferior, do 47,6\%. Por tanto, os desequilibrios do proceso de acumulación, á súa vez, deron co resultado dunha diverxencia en canto ao encarecemento dos diversos activos integrantes do stock de capital.

Na figura 5 destaca que os deflactores de prezos relacionados co auxe da construción aumentou entre 1995 e 2007 en moita maior medida co resto. O prezo dos activos materiais de vivendas e outras construcións aumentaron un 92,7 e 67,4\% respectivamente, o que contrasta co equipo de transporte e a maquinaria, equipo e outros activos, cuxos prezos apenas aumentaron entre o 19 e o $25 \%$. Pola súa banda, os activos inmateriais como o software experimentaron un abaratamento en termos absolutos de case o $20 \%$.

\section{Figura 5. Incremento dos prezos dos distintos activos do stock de capital fixo}

Taxa de variación dos deflactores en porcentaxes entre 1995 y 2007

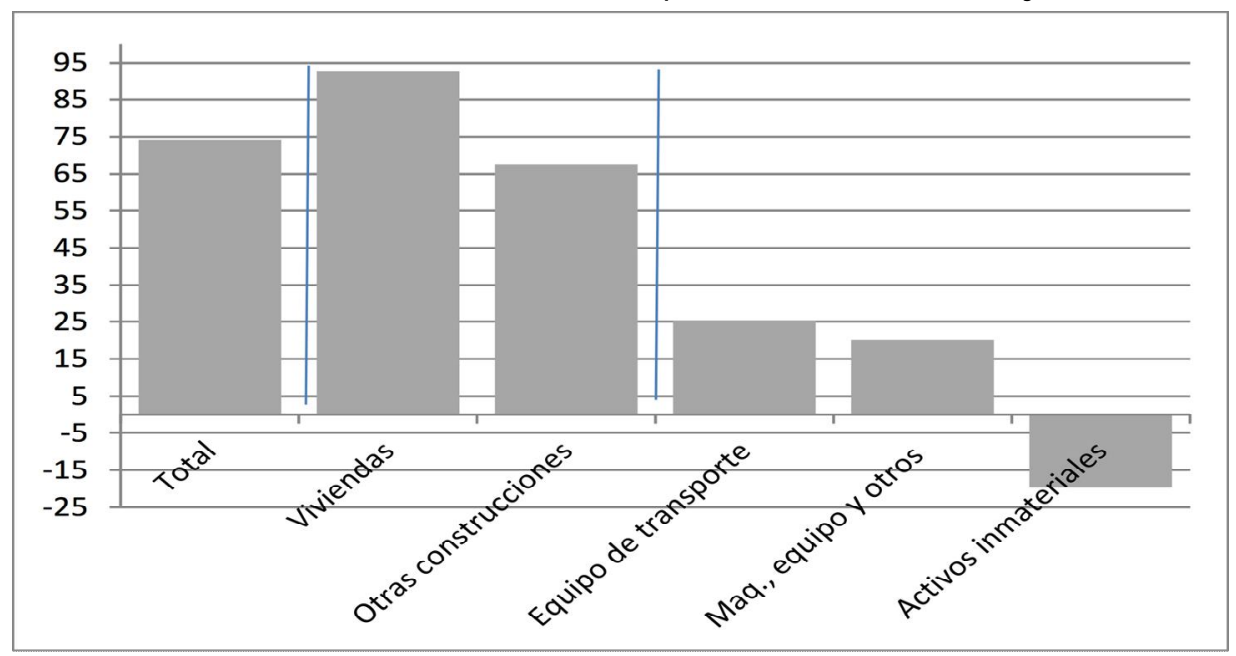

Fonte: FBBVA (2014)

Nótese que dende a metade dos anos sesenta do século pasado, o stock de vivendas encarecou relativamente máis co resto de activos, pero a un ritmo de 10 puntos porcentuais inferior ao vixente en 1995-07. O contraste prunfúndase cando abordamos 0 equipo de transporte e a maquinaria e equipo. Nas décadas anteriores, os seus deflactores aumentaron o 70-73\% do total, polo que a caída experimentada durante o ciclo expansivo que se inicia en 1995, no cal os seus prezos só aumentan algo máis dun terzo da media total, ilustra o grao de diverxencia ou relativo dualismo e de desequilibrios desta fase. É máis, ata dentro deste lapso, os prezos dos dous non seguen un camiño relativamente paralelo, pois namentres os equipos de transporte se abaratan relativamente ao longo deste período, os activos da maquinaria, equipos e outros posúen unha evolución nos seus prezos oposta, pois entre 2003 e 2007 o seu aumento medio anual é do 55\% do total.

\subsection{Acumulación e desenvolvemento produtivo}

O proceso de capitalización por parte das empresas dunha parte dos beneficios recolleitos materialízase na ratio capital-traballo $(\mathrm{K} / \mathrm{L})$, que constitúe un índice da mecanización do 
proceso produtivo (véxase Mateo, 2008). Este índice é significativo porque supón o fundamento esencial, aínda que non exclusivo, da mellora da produtividade laboral. ${ }^{7}$

Como vimos, a evolución á alza do stock de capital fixo non residencial a prezos contantes mantén certa homoxeneidade ao longo do período, cunha taxa anual media do 4,6\%. A creación de emprego, porén, amósase máis volátil, xa que entre 1996 e 2000 crece a unha media do 4,4\%, pero a partir de 2000 o incremento cae ao $2.8 \%$ anual. Este elevado ritmo de creación de postos de traballo, do 3,3\% por ano, trae consigo un dos principais trazos do proceso de acumulación en España, que son: o reducido dinamismo da ratio capitaltraballo, o que terá implicacións sobre a produtividade. Así, este índice da mecanización produtiva apenas aumenta un 16\% en 13 anos, o que constitúe un rexistro moi baixo. Se en 1995-00 se incrementa ao 0,55\% anual, na fase posterior de 2000-07 é sensiblemente superior, do 1,75\% anual. Pero como se amosou, o auxe de K/L non se debe principalmente a unha intensificación no ritmo de crecemento de $K$, senón na menor creación de emprego con respecto á fase anterior, malia que o aumento da masa de acervo de capital fixo é destacable.

7 Impóñense varios esclarecementos: i) a aseveración do papel fundamental da ratio K/ L para explicar a dinámica produtiva non implica descoñecer fenómenos como cambios organizativos que melloren a produtividade sen alterar $\mathrm{K}$, nin cambios no contexto que igualmente impliquen un resultado análogo; ii) ao falar de produtividade laboral non consideraremos o tempo de traballo polas limitacións que teñen a súa medida, polo que, a falta dunha explicación mellor, tomaremos como indicador (imperfecto), o PIB por cantidade de traballo equivalente total. 
Figura 6. A ratio capital-traballo

Ratio K/ L en índices (1995=100) e en taxas de variación anual, xunto aos seus compoñentes, o stock de capital e a cantidade de traballo

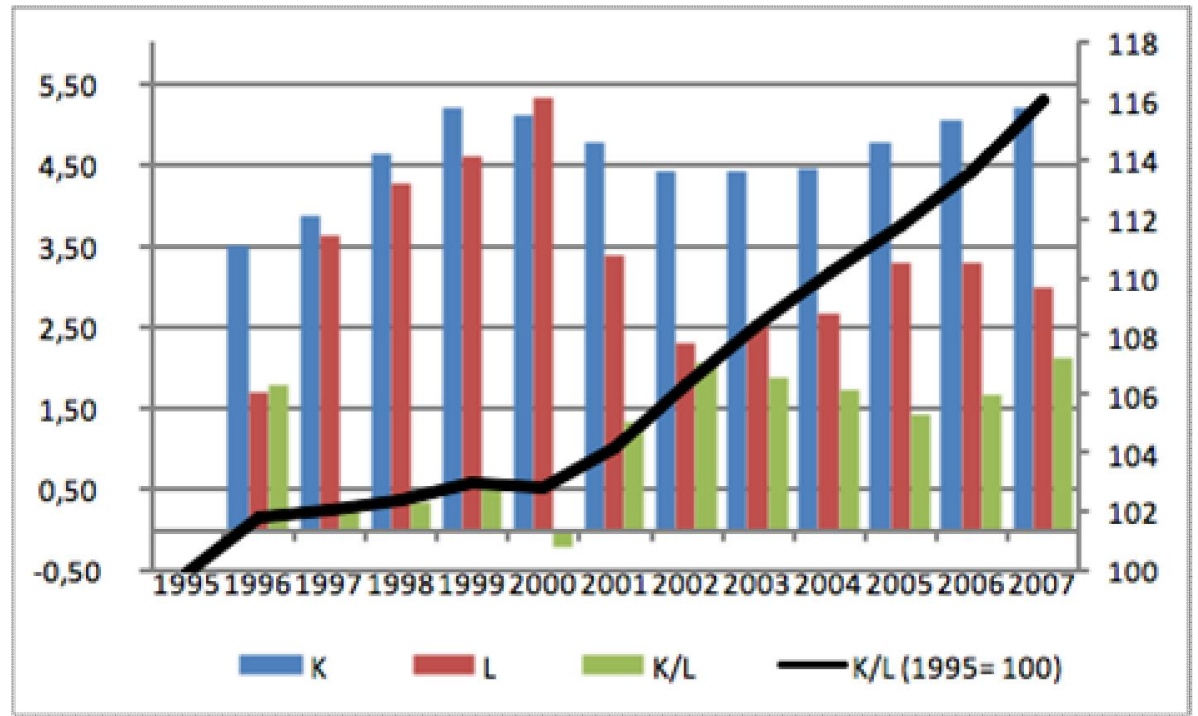

Notas. Ratios capital-traballo $(\mathrm{K} / \mathrm{L})$, produtividade laboral $(\mathrm{PIB}=\mathrm{Y} / \mathrm{L})$, ratio dos deflactores de prezos do produto $\left(\mathrm{P}_{\mathrm{Y}}\right)$ e do stock de capital $\left(\mathrm{P}_{\mathrm{K}}\right)\left(\mathrm{P}_{\mathrm{Y}} / \mathrm{P}_{\mathrm{K}}\right)$ e produtividade do capital ou ratio produto-stock de capital (Y/K). Considérese que $\mathrm{Y} / \mathrm{K}=[(\mathrm{Y} / \mathrm{L}) /(\mathrm{K} / \mathrm{L})] \mathrm{x}(\mathrm{PY} / \mathrm{PK})$. Fonte: FBBVA (2014), INE (2014)

A importancia da mecanización do proceso produtivo derívase do seu papel na mellora da produtividade laboral. En gran medida, $\pi=f(\theta)$, o que á súa vez se reflicte na produtividade do capital ou taxa máxima de ganancia, e, por tanto, de crecemento da economía.

$\Pi=\frac{\pi}{\theta} \frac{P_{Y}}{P_{K}}$

A produtividade do capital ( $\Pi$ ) depende de canto aumente a produtividade laboral $(\pi)$ en relación á ratio $\mathrm{K} / \mathrm{L}(\theta)$, é dicir, a eficiencia produtiva do investimento (EPI), así como a relación de prezos $(\mathrm{P})$ : 0 abaratamento relativo do stock de capital $\left(\mathrm{P}_{\mathrm{K}}\right)$ con respecto ao produto total $\left(\mathrm{P}_{\mathrm{Y}}\right)$.

$E P I=\frac{\Delta \pi}{\Delta \theta} \Rightarrow \mathbb{I}=f(E P I, P)$

As particularidades amosadas da acumulación tiveron consecuencias importantes, que podemos visualizar na figura 7. A dinámica da produtividade laboral foi profundamente negativa, xa que o incremento acumulado foi do 4,4\%. Se o cuasi-estancamento de K/ L no primeiro subperíodo trouxo consigo un aumento da produtividade laboral de 1,7 puntos porcentuais inferior, cando nos seguintes anos a mencionada ratio $\mathrm{K} / \mathrm{L}$ crece con maior intensidade, resulta que a produtividade laboral crece relativamente menos, ata 8,5 puntos. A eficiencia produtiva do investimento, pois, baixou, malia que o ritmo de "crecemento" de Y/ L foi o duplo a partir de 2000 (fig. 8). 
Figura 7. Indicadores de produtividade, laboral e do capital, e ratio de deflactores de prezos $(1999=100)$

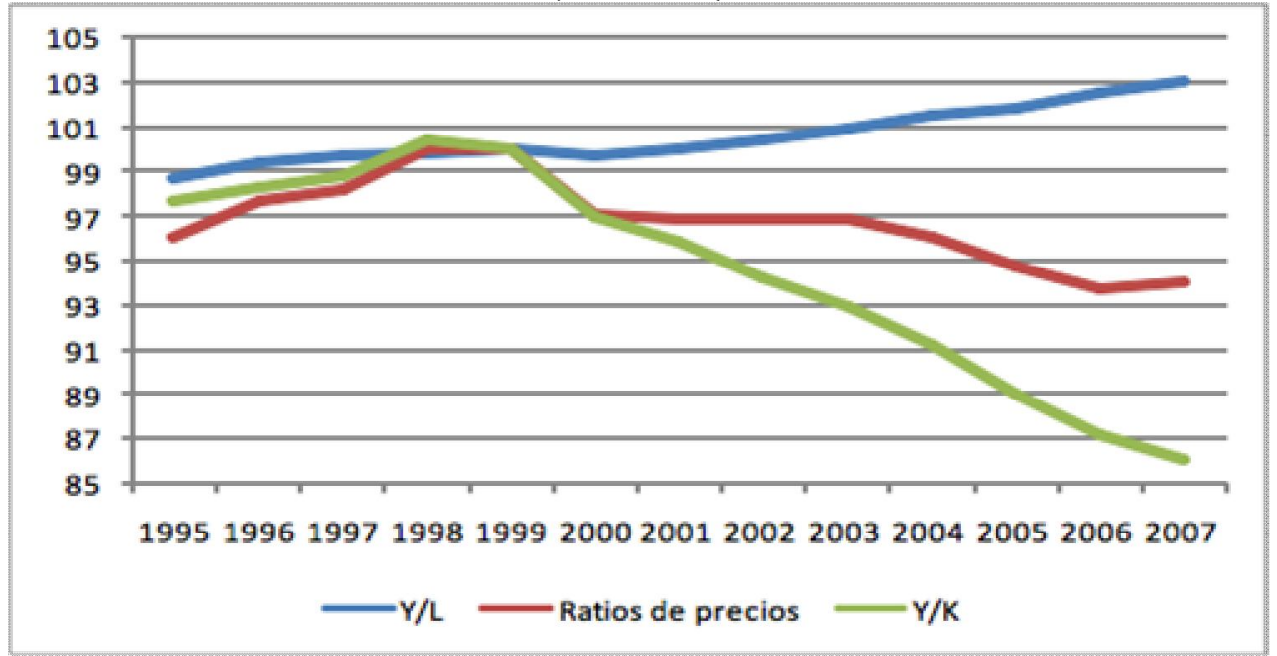

Notas. Y/ L: produtividade laboral; $\mathrm{P}_{\mathrm{Y}} / \mathrm{P}_{\mathrm{K}}$ : ratio do deflactor de prezos de $\mathrm{Y}\left(\mathrm{P}_{\mathrm{Y}}\right)$ con respecto a $\mathrm{K}$ ( $\mathrm{P}_{\mathrm{K}}$; Y/ K: ratio produto-capital. Fonte: FBBVA (2014), INE (2014)

Figura 8. A eficiencia produtiva do investimento

Ratio dos incrementos da produtividade laboral con respecto aos correspondentes á relación capital-traballo (\%)

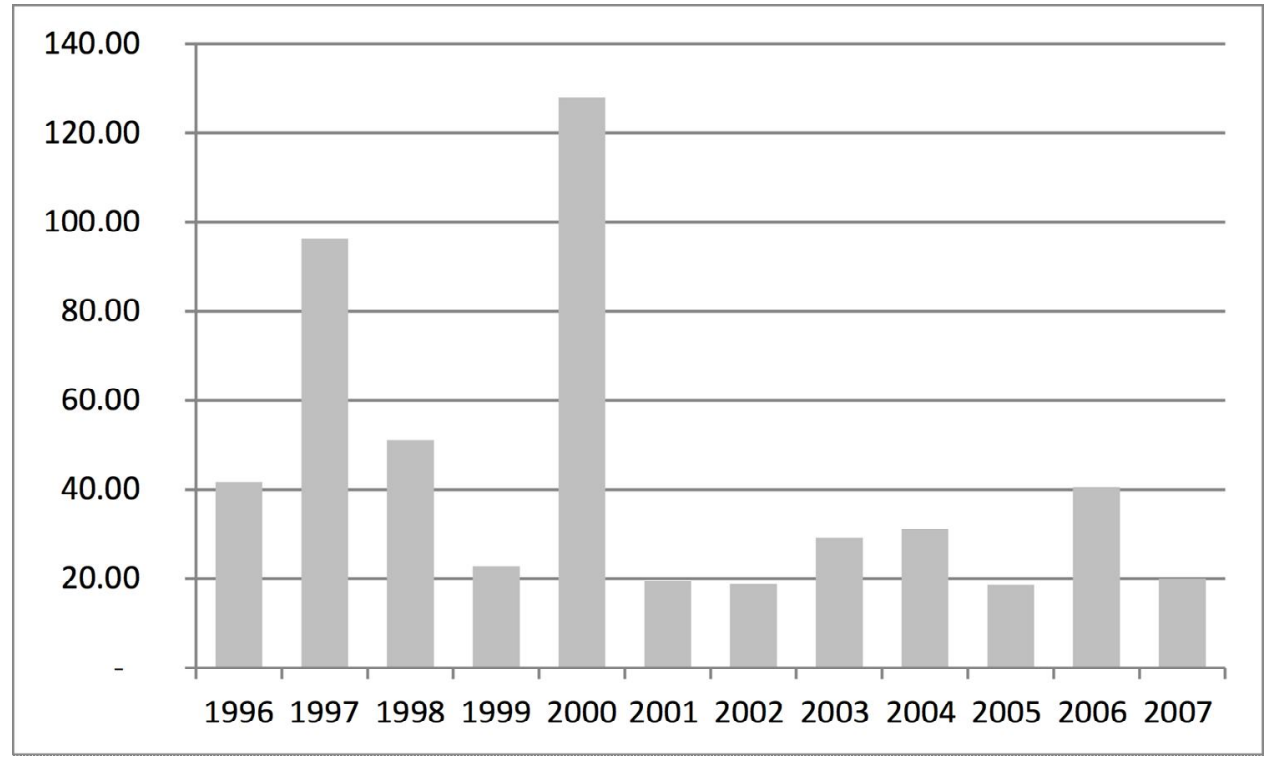

Fonte: FBBVA (2014), INE (2014)

Coas excepcións de 1997 e 2000, apréciase que a EPI é moi reducida, pois en xeral atópase por debaixo do $40 \%$, concretamente no $29,3 \%$. Noutras palabras, a produtividade laboral aumenta algo menos da terceira parte do incremento do volume do stock de capital por traballador.

A ratio dos deflactores de prezos, aínda cunha variación que non foi substancial, foi tamén en detrimento do proceso de acumulación. O cociente $\mathrm{P}_{\mathrm{Y}} / \mathrm{P}_{\mathrm{K}}$ aumentou un 4,1\% ata 1998- 
99, para descender posteriormente un $6 \%$. Dende a nosa perspectiva, significa que o stock de capital encarecéuse con respecto ao nivel xeral de prezos a partir de 1999, precisamente cando se establecen os tipos de cambio fixos. ${ }^{8}$ Mentres, a competencia e o cambio tecnolóxico expresada por medio dos prezos (Shaikh, 1990) supoñen un atraso ou menor dinamismo producivo das ramas relacionadas co stock de capital e/ ou un maior prezo cando que se importa do exterior. ${ }^{9}$ Por tanto, o descenso da ratio de prezos relaciónase cos problemas da capacidade produtiva da economía española no sector de bens de capital.

Consecuencia destes dous aspectos, a eficiencia produtiva do investimento e a relación de prezos (á súa vez relacionados entre eles), é a evolución da produtividade do capital (II). Esta ratio amosa unha clara tendencia descendente agás nos primeiros anos. Entre 1995 e 1998, o estancamento do $\mathrm{K} / \mathrm{L}$ (iso si, co correspondente $\mathrm{Y} / \mathrm{L}$ ), unido ao abaratamento relativo do stock de capital, supuxo que II aumentase nun 2,8\%, namentres que ao ano seguinte rexistrou unha caída insignificante $(-0,45 \%)$. Porén, e como sucedeu coa ratio de deflactores de prezos, comeza posteriormente a descender, pero a un ritmo superior. Entre 1999 e 2007 cae un 13.8\% acumulado, o que representa unha media do $-1,8 \%$ anual.

Por tanto, a partir de 1999-2000 a dinámica de acumulación de capital presenta unha serie de problemas agravados. Malia que o ritmo de expansión do stock de capital é relativamente elevado, o sector dos bens de capital (ou, fóra iso, a dipoñibilidade destes elementos) atopa obstáculos para o desenvolvemento produtivo. Dende 1999-2000, $\theta$ crece case un 13\%, namentres $\mathrm{Y} / \mathrm{L}$ apenas supera o $3 \%$ e o encarecemento relativo de $\mathrm{K}$ chega ao 6\%. É dicir, a acumulación de capital intensifícase, pero cun encarecemento dos bens de capital e un menor dinamismo relativo da produtividade laboral, todo o cal presiona á baixa a produtividade do capital, que á súa vez limita a rendibilidade máxima.

\subsection{Os custos de produción}

Constátase un segundo problema neste proceso de acumulación que estudamos, ou máis ben unha consecuencia do analizado no apartado anterior. O percorrido da mecanización e a reducida capacidade de desenvolver a produtividade tiveron como consecuencia o aumento dos custos de produción. O corolario non puido ser outro que unha especialización produtiva en segmentos de tecnoloxía media-baixa e a deterioración da competitividade exterior da economía española, evidente pola cantidade e tipoloxía das importacións, xunto co déficit crecente da balanza comercial, amplificando un trazo previo da economía española (véxase García, 2014).

Porén, esclarecemos o senso teórico do "custo de produción" dende a perspectiva deste estudo. Na medida que consideramos a acumulación de capital como o fundamento do crecemento económico, adoptamos unha perspectiva dinámica na que non consideramos ao suxeitos económicos (esencialmente, as unidades empresariais), como meros axentes pasivos prezo-aceptantes nun marco de competencia perfecta (Shaikh, 1990). A competencia entre empresas realízase mediante o abaratamento das mercadorías, polo que o desenvolvemento produtivo está estreitamente ligado á progresiva redución dos custos de produción por unidade de produto ${ }^{10}$.

8 A modo de recordatorio, esclarecemos que utilizamos o deflactor de prezos do stock de capital non residencial.

9 En todo caso, a necesidade de importar elementos deste stock reflicte unha ausencia de competitividade, polo que se vencella co menor desenvolvemento produtivo.

10 Daí que vencellemos o desenvolvemento cos deflactores de prezos. 
Os custos totais de produción (CT) están compostos por insumos ou consumos intermedios (CI) e remuneracións salariais (RA), polo que $C T=C I+R A$.

$$
\frac{C T}{Y}=f\left(\frac{Y}{L}\right) \Rightarrow\left\{\frac{K}{L}, \frac{Y}{L} \rightarrow C T U\right\}
$$

Onde os custos totais por unidade de produto ( $C T U=C T / Y$ ) dependen da produtividade (Y/L) acadada a partir da acumulación de capital, materializada na cantidade de capital fixo por unidade de traballo (K/L). Por tanto, o investimento relativamente superior en elementos de capital fixo por unidade de traballo e de produto constitúe o mecanismo esencial para acadar economías de escala (Shaikh, 1990), reducindo deste xeito os custos unitarios de produción. Esta tendencia implica á súa vez un cambio na composición destes custos, namentres o seu nivel absoluto debe tender a reducirse: i) unha maior porcentaxe de custos non laborais por unidade de produto, asociados ao aumento na utilización de activos de capital fixo; ii) a posibilidade de que os salarios en termos absolutos (ou reais) aumenten, simultaneamente a un descenso na súa dimensión relativa (como se expresou no punto anterior); iii) un aumento dos custos de depreciación do stock de capital utilizado.

Os custos totais en relación ao valor agregado bruto aumentaron un 19,7\% ao longo do período, pasando así de representar o 146\% en 1995 a superar o 170\% nos tres últimos anos, de 2005 a 2007. Mentres os custos salariais mantiveron un nivel constante en torno ao 53-54\% do valor agregado bruto (VAB), os insumos, que en 1995 supoñían o 93,8\% do produto, en 2006-07 xa superaban o 120\%. Como consecuencia, os 19 puntos porcentuais que aumentaron a ratio CT/ VAB reflicten exactamente o incremento de CI/ VAB.

\section{Figura 9. Os custos dos insumos e as remuneracións salariais con respecto ao valor agregado bruto}

Serie a prezos correntes en porcentaxes

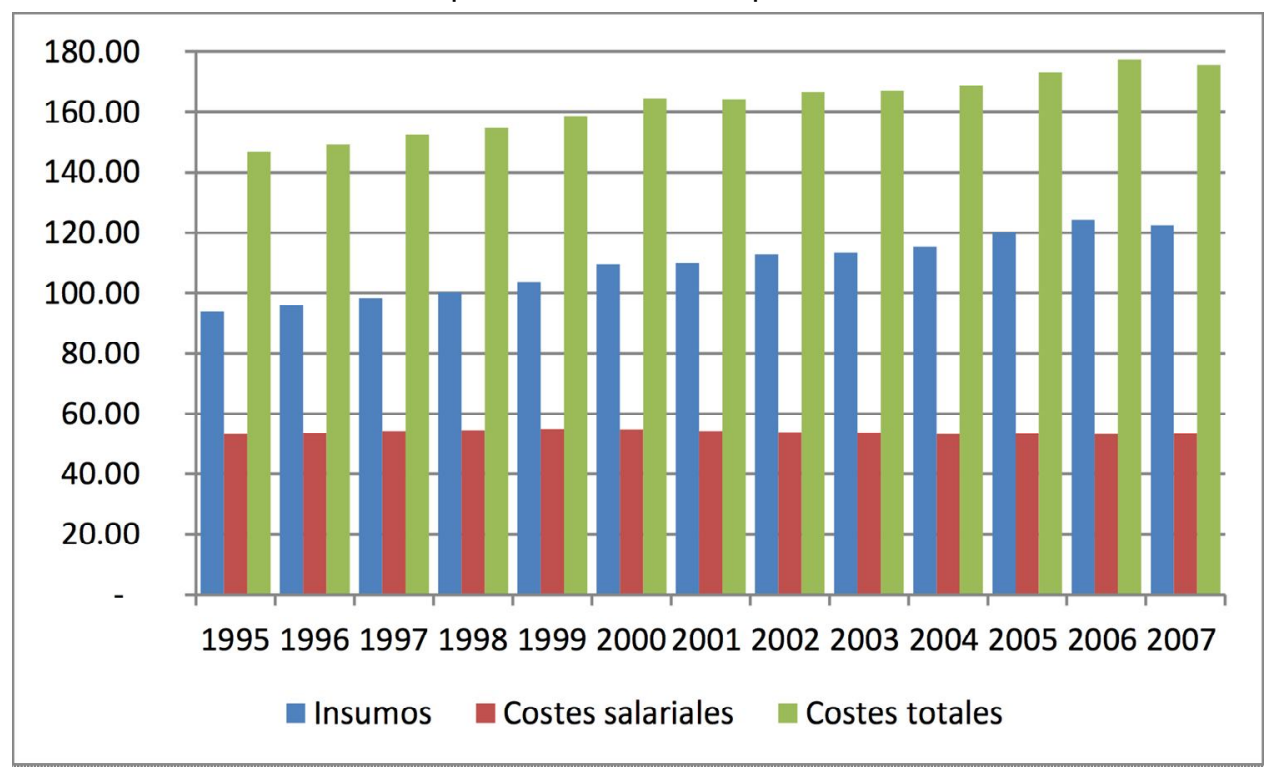

Fonte: INE (2014) 
Do exposto, pódese entender o marco produtivo que imposibilitou o aumento dos salarios (RA). O incremento da taxa de asalarización, que pasou do $80,5 \%$ en 1995 ao $86,4 \%$ en 2007 (INE, 2014), foi paralela a unha perda do poder adquisitivo do salario medio. Malia é certo que en relación ao IPC o salario medio aumenta un 1,26\% ao longo do período segundo AMECO (2014), se tomamos o deflactor do PIB, considerando o encarecemento dun ben de consumo duradeiro como a vivenda, atopámonos cunha caída do salario real medio do 4,70\%, que sería do $6 \%$ se tomamos como referencia o período 1996-06 (INE, 2014). Esta dinámica regresiva permitiu á súa vez compensar os desequilibrios do proceso de acumulación, ata posibilitando unha redución dos custos laborais reais unitarios (CLRU). ${ }^{11}$

$C L R U=\frac{\frac{R A}{L_{W}}}{\frac{Y}{L_{g}}}$

Onde os CLRU que calculamos (proxy da medida ideal) relacionan as remuneracións (RA) dos traballadores asalariados $\left(\mathrm{L}_{\mathrm{w}}\right)$ co produto por traballador $(\mathrm{Y} / \mathrm{L})$, ou posto de traballo equivalente $\left(\mathrm{L}_{e}\right)$, tendo en conta que $\mathrm{L}_{\mathrm{w}}$ representa máis do $80 \%$ de $\mathrm{L}_{\mathrm{e}}$. Ata 2006 , os CLRU descenden un $9,52 \%$, xa que os salarios caíron un $5,86 \%$ e a produtividade aumentou case un $4 \%$. Como consecuencia, a regresividade distributiva contribuíu en maior medida á redución dos custos laborais en termos reais.

11 Tanto as remuneracións como o PIB están expresados a prezos constantes utilizando o mesmo deflactor de prezos, o do produto total, polo que non se pon na expresión debida a que está no numerador e no denominador. Porén, o PIB a prezos constantes tómase do que proporciona o INE, namentres que o deflactor utilizado para o salario é o derivado de dividir os PIB a prezos correntes e constantes. Por outra banda, mencionemos o noso desacordo con relacionar salarios a prezos correntes co PIB a prezos constantes, polo que homoxeneizamos as dúas categorías. 
Figura 10. Os custos laborais reais unitarios e os seus compoñentes: salario real medio e produtividade laboral $(1995=100)$

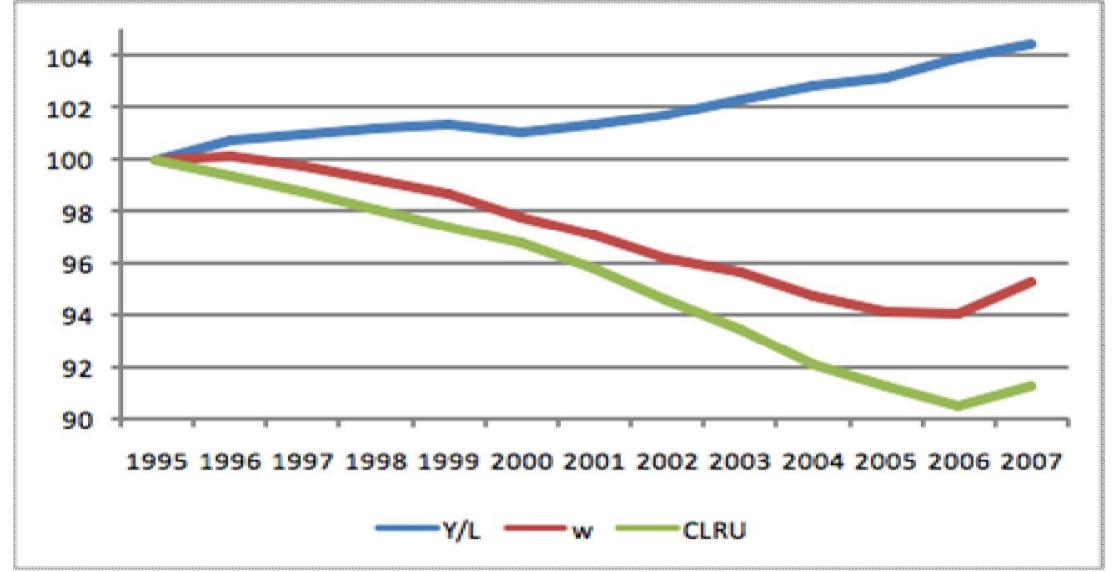

Nota: CLRU: custo laboral real unitario; Y/L: produtividade laboral $(\pi)$; w: salario real medio (remuneracións totais por traballo asalariado equivalente deflactado polo índice de prezos do PIB), sendo $\mathrm{CLRU}=\mathrm{w} / \pi$. Fonte: $\operatorname{INE}(2014)$

\section{Conclusións}

Esta investigación pretendeu contribuír á comprensión dos desequilibrios da economía española durante a fase de expansión (1995-2007) a partir do proceso de acumulación de capital. A temática resulta pertinente en tanto que a formación de capital constituíu o motor do crecemento, aínda que cun profundo nesgo cara a vivenda e outras construcións, que chegaron a representar máis do 70\% de media do total durante o lapso 2003-07.

O elemento subxacente foi o "efecto prezo", característico do papel adquirido pola inflación de activos da construción e, en concreto, residenciais. $\mathrm{O}$ aumento extraordinario dos prezos destes activos da construción e, concretamene, residenciais. $\mathrm{O}$ aumento extraordinario dos prezos destes activos xerou unha dualidade en distintas variables a prezos correntes e constantes que presidiu o proceso estudado: o deflactor de prezos de $\mathrm{K}$ en construción e vivendas aumento un 67 e 92\% ao longo do período, respectivamente, mentres que os prezos do resto de activos de transporte, maquinaria e equipo só aumentaron un $19-25 \%$.

A pesar do dinamismo do stock de capital non residencial, a ratio K/ L permaneceu case estancadoa, apenas cun $16 \%$ de crecemento, e en verdade limitada á subfase posterior ao ano 2000. A produtividade laboral só aumentou un preocupante $4,4 \%$ total, e ademais, a eficiencia produtiva do investimento baixa dende 2000. Ademais, amosa un nivel absoluto alarmantemente reducido, pois excluíndo 1997 e 2000, nin sequera chega ao 30\% de aumento de Y/L con respecto ao aumento en K/ L. Unido a esta caída, o stock de capital (non residencial) encareceuse con respecto ao produto total dende 1999, como o proba 0 seu deflactor de prezos.

En consecuencia, os custos totais aumentaron un 19,7\% con respecto ao VAB, o que reflectiu o aumento do custo dos insumos. O custo salarial relativo permaneceu constante, e ata os CLRU baixaron polo descenso do salario real medio (deflactado polo nivel de 
prezos total), malia o feble comportamento da produtividade. Destacamos que ata 2006 os CLRU caen un $9,5 \%$ e o salario real un 5,8\%. O percorrido comparado da ratio $\mathrm{K} / \mathrm{L}$, a produtividade laboral e a relación de prezos da como resultado a produtividade do capital. Un dos aspectos máis relevantes obtidos é a caída do 14\% da ratio Y/ K entre 1999 e 2007, derivada tanto da "ineficiencia produtiva do investimento" como do aumento relativo de $\mathrm{P}_{\mathrm{K}}$.

\section{Bibliografía}

AMECO (2014): Annual macro-economic database. Comisión Europea, Asuntos Económicos y Financieros.

BAIGES, J.; MOLINAS, C.; SEBASTIÁN, M. (1987): La economía española 1964-1985: datos, fuentes y análisis. Madrid: Instituto de Estudios Fiscales.

BRENNER, R. (2006): La economía de la turbulencia global. Madrid: Akal, 2009.

CORRALES, A.; TAGUAS, D. (1989): Series macroeconómicas para el período 1954-88: un intento de homogeneización. Madrid: Instituto de Estudios Fiscales.

FONDO MONETARIO INTERNACIONAL (FMI) (2013): World economic outlook database, octubre. Washington D.C.: Fondo Monetario Internacional.

FUNDACIÓN BANCO BILBAO VIZCAYA ARGENTARIA (FBBVA) (2014): El stock y los servicios del capital en España y su distribución territorial y sectorial (1964-2012). Madrid: FBBVA/ Instituto Valenciano de Investigaciones Económicas (Ivie).

GARCÍA, N. (2014): "La débil competitividad de la economía española", en N.E. García y S.M. Ruesga [coords.]: Que ha pasado con la economía española? La Gran Recesión 2.0 (2008 a 2013), pp. 117-150. Madrid: Pirámide.

INSTITUTO NACIONAL DE ESTADÍSTICA (INE) (2014): Contabilidad nacional de España. Base 2008. Serie homogénea 1995-2012. Madrid: Instituto Nacional de Estadística.

MARTÍN, A.; MORENO, L. (1991): Medidas del stock de capital a partir de los datos contables. (Documento de Trabajo 9103). Madrid: Programa de investigaciones económicas, Fundación Empresa Pública.

MATEO, J.P. (2008): La Tasa de ganancia en México, 1970-2003. Análisis de la crisis de rentabilidad a partir de la composición del capital y la distribución del ingreso. Tesis doctoral, Universidad Complutense de Madrid.

RODRÍGUEZ, E.; LÓPEZ, I. (2011): “Del auge al colapso. El modelo financiero-inmobiliario de la economía española”, Revista de Economía Crítica, 12, pp. 39-63.

SHAIKH, A. (1990). Valor, acumulación y crisis. Bogotá: Tercer Mundo Editores.

Revista Galega de Economia at Ideas: http:// https:/ / ideas.repec.org/ s/ sdo/ regaechtml

Bulletin and News of Revista Galega de Economía at: http:/ / www.usc.es/ econo/ RGE/ benvidag.htm 